\title{
Skin cancer medicine integral to Australian general practice
}

\section{Stephen A Margolis}

Details make perfection, and perfection is
not a detail.

- Leonardo da Vinci

Skin cancer medicine is a core component of Australian general practice and is consistently in the top 10 conditions managed. ${ }^{1}$ This is not surprising as Australia has the highest incidence of melanoma in the world,${ }^{2}$ leaving melanoma the fourth most common cancer in Australia, especially in non-metropolitan locations. ${ }^{3}$ Across the 20-year period 1995-2014, melanoma incidence in Queensland remained the highest recorded in the world (age-standardised incidence of invasive melanoma 572 per 100,000/annum [2010-2014]). ${ }^{4}$

Widespread public information campaigns have been effective; currently, approximately half of all new diagnoses of melanoma are initially noticed by the patient, who then approaches their clinician, usually their general practitioner (GP), for advice. ${ }^{5}$ This is leading to earlier detection, known to improve survival, with the incidence of in situ melanoma rising while the incidence of invasive melanoma is stable or falling in patients aged under 60 years. ${ }^{4}$ The management of melanoma continues to evolve, with the latest changes for both cutaneous and metastatic melanoma explored by Dixon et al. ${ }^{6,7}$

GPs are well positioned to play a key part in skin cancer medicine, with diagnostic acumen of similar high sensitivity and accuracy to formal skin cancer doctors. ${ }^{8}$ Overall management of skin cancer in general practice is of similar quality and effectiveness to that provided by skin cancer clinic networks. ${ }^{9}$ Similarly, despite patients with cutaneous melanoma having a high risk of recurrence and hence requiring careful follow-up, GP-led follow-up for melanoma has been shown to be as effective as hospital-based care. ${ }^{10}$

What is perhaps unusual about skin cancer medicine when compared with other aspects of general practice is the type of skill required to perform diagnosis. Although the history is important, the action plan is primarily determined by carefully considering the fine details of the appearance of the individual lesion, perhaps enhanced by viewing through a dermatoscope. In addition, the formal diagnosis requires a surgical intervention rather than sending the patient to another service for imaging or pathology testing. Note that clinically suspicious pigmented lesions require excision rather than limited biopsy, as explained by Adybeik et al. ${ }^{11}$

As such, skin cancer diagnosis and management would perhaps appear more intensive in time, observation, physical dexterity skills and attention to detail than other areas of clinical practice. Some of the required skills are generic and learned across the spectrum of clinical medicine, while others are unique to skin cancer medicine. The latter are perhaps best formalised as having both a structured approach to what you see plus a high level of attention to detail.

As with most areas of clinical practice, findings can be divided into three groups: clearly normal/benign lesions, clearly abnormal/malignant lesions and lesions for which provenance is uncertain. The breadth of the third group will narrow with the GP's training and experience, while the disposition of the patient will be either excision for definitive pathological diagnosis or referral to someone with additional skills. For example, Clarke explains, 'If there is significant doubt about a seborrhoeic keratosis, the lesion should be biopsied or carefully reassessed in eight weeks, or the patient sent for a second opinion'. ${ }^{12}$

With Australia the epicenter for melanoma and general practice a key port of call for patients who are worried about pigmented spots on their skin, GPs are ideally positioned for their pivotal role in diagnosis and management.

\section{Author}

Stephen A Margolis, OAM; senior medical editor at Australian Journal of General Practice; Professor, School of Medicine, Griffith University, Qld; and Senior Staff Specialist, Capricorn Coast Hospital, Qld, and the Royal Flying Doctor Service.

\section{References}

1. Britt H, Miller GC, Bayram C, et al. A decade of Australian general practice activity 2006-07 to 2015-16. General practice series no. 41. Sydney: Sydney University Press, 2016.

2. Australian Institute of Health and Welfare. Cancer in Australia: An overview 2010. Canberra: AlHW, 2010.

3. Australian Institute of Health and Welfare. Health system expenditure on cancer and other neoplasms in Australia: 2008-09. Cancer series no. 81. Cat. no. 78. Canberra: AIHW, 2013.

4. Aitken JF, Youlden DR, Baade PD, Soyer HP, Green AC, Smithers BM. Generational shift in melanoma incidence and mortality in Queensland, Australia, 1995-2014. Int J Cancer 2018;42(8):1528-35. doi: 10.1002/ijc.31141.

5. Emery, J. Melanoma: Improving diagnosis in general practice. Aust Fam Physician 2011;40(12):991.

6. Dixon AJ, Steinman HK, Nirenberg A, Anderson S, Dixon JB. Cutaneous melanoma: Latest developments. Aust J Gen Pract 2019;48(6):349-53.

7. Dixon AJ, Steinman HK, Nirenberg A, Dixon ZL, Anderson S, Dixon JB. Management of invasive melanoma. Aust J Gen Pract 2019;48(6):368-72.

8. Youl PH, Baade PD, Janda M, Del Mar CB, Whiteman DC, Aitken JF. Diagnosing skin cancer in primary care: How do mainstream general practitioners compare with primary care skin cancer clinic doctors? Med J Aust 2007;187(4):215-20. doi: 10.5694/j.1326-5377.2007.tb01202.x

9. Ackermann E, Askew D, Williams ID, Byrnes P, Mitchell GK. Management of skin cancer in Australia: A comparison of general practice and skin cancer clinics. Aust Fam Physician 2007;36(12):1073-75.

10. Murchie P, Nicolson MC, Hannaford PC, Raja EA Lee AJ, Campbell NC. Patient satisfaction with GP-led melanoma follow-up: A randomised controlled trial. Br J Cancer 2010;102(10):1447-55. doi: 10.1038/sj.bjc.6605638.

11. Adybeik D, Ciranni D, Moayed Alaei L. Punch biopsy is best avoided for clinically suspicious pigmented lesions. Aust J Gen Pract 2019;48(6):354-56.

12. Clarke P. Benign pigmented skin lesions. Aust J Gen Pract 2019;48(6):364-66. 